\title{
Knowledge Generation Managing at Universities
}

\author{
M.V. Vlasov \\ PhD in Economics, Senior Research Assistant of the Institute of Economics, \\ The Ural Branch of the Russian Academy of Sciences \\ Email:mvlassov@mail.ru
}

\section{Doi:10.5901/mjss.2015.v6n1p453}

\section{Abstract}

The present paper compares the dynamics of research output of universities, which is expressed quantitatively, with the dynamics of transaction funds spending. Transaction costs are found to determine research performance of universities in terms of publishing research papers, obtaining patents, and participation in conferences and exhibitions. The paper empirically verifies the hypothesis that the transaction rate of knowledge generation expressed as participation in exhibitions in directly proportional to the number of economic units established at universities with the purpose of promoting the application of research achievements. The transaction rate of knowledge generation in the form of conference presentations is shown to be directly proportional to the university contractual work per capita.

Keywords: Knowledge generation, Transaction costs, Research papers, Patents, Conference presentations.

\section{Introduction}

We are now a witness to boosting the role of knowledge in economic activity virtually at all levels of economy. This is primarily because the world is rapidly shifting to another development stage, the core of which is going to constitute the economy based on knowledge. A distinct feature of the latter is knowledge playing the crucial role, with its generation becoming an impetus for economic growth.

The analysis of world universities allows one to conclude that all sorts of funding there serve the primary function of any university - to distribute knowledge in society. Anything hampering its realization is considered unwelcome, and any commercial activity beyond knowledge transfer is seen as a principal cause of conflict of interests. That is why the need to scrutinize university research performance poses the challenge of great research relevance.

The objective of the present work is to estimate the correlation between the dynamics of university research output, which is measured quantitatively, and the dynamics of spending the transaction funds.

The investigation is organized according to the following research logic: 1) examination of the preceding bulk of research, 2) drawing up work hypotheses, 3) discussion of the empirical investigation procedure, 4) obtaining empirical data, 5) verification of the work hypotheses.

\section{Research Background}

B.R. Clark was the first to outline and elucidate three main perspectives of the university activity. The fundamental perspective of traditional universities suggests serving own academic ideals; the applied perspective, which is realized commercial universities, is focused on realization of ideas having commercial potential; the research work of a sociallyoriented university is aimed at objectives set by the society and the government (Clark B.R., 1983).

The issues of evaluating performance of academic organizations have drawn the attention of many distinguished economic scholars. Thus, Bjørnåli E. S. and Gulbrandsen M. in 2010 addressed the ways of increasing profit of academic organizations by managerial stimulation of research performance (Bjørnåli E. S.and Gulbrandsen M., 2010). Nilsson A. S., Rikne A. and Bengtsson L. looked at promoting and increasing the cost of academic activity outcome (Nilsson A. S., Rikne A.and Bengtsson L., 2010). The issues of the cost of academic output transfer drew the attention of Zinkhan G. M., who saw the potential of reducing the costs of knowledge generation in its distribution through electronic media (Zinkhan G. M., 2008). Visser Evert-Jan tried to assess the transaction costs of generation and distribution of academic output (Visser Evert-Jan, 2007). The authors of the present paper turned to the matters of institutional analysis of knowledge generation (Popov E.V., Vlasov M.V., 2008).

K. Arrow believed transaction costs to be those of exploitation in an economic system (1994). He compared the 
influence of transaction costs on economy with the phenomenon of friction in physics. Such ideas brought about a conclusion, that the closer an economy comes to the Walras's general equilibrium model the lower the level of transaction costs it demonstrates, with the opposite being as true.

On the other hand, D. North determined transaction costs as those consisting of 'the costs of assessment of useful properties of exchange goods and the costs of property rights security and enforcement on their execution'. These costs were assumed the source of social, economic and political institutions (North D.C., 1981).

Taking the K. Arrow and D. North's beliefs for granted, we define the cost assessment of an economic institution as the transaction costs of establishing the norm of interaction between economic agents.

The need to consider transaction costs when investigating knowledge generation is clearly justified by the works of D. North, J. Wallis, and O. Williamson. The research of J. Wallis and D. North, devoted to transaction costs on macroeconomic level, showed the economic growth of a country to cause the expansion of its transaction sector (Wallis J., North D., 1986). Therefore, the growth of knowledge, which is a factor of economic development, is determined by a change in the transaction cost rate. The development of innovation activity is often followed by transactions with highly specific assets. It was O. Williamson who first highlighted the problem of asset specificity (Williamson O. E., 1979). This feature also indicates the need to elucidate the correlation between knowledge and transaction costs in an organization.

The previous research allowed us to single out two types of transaction costs in academic organizations. In the academic sector of science, the vast majority of transaction costs of knowledge increase are the costs of information search and the costs of negotiations (Popov E.V., Vlasov M.V., 2012).

We earlier also showed that, in terms of production companies, the knowledge increase is determined by the dynamics of transaction costs (Popov E.V., Vlasov M.V., 2013). Similarly, in turn, the transaction costs change effects knowledge generation in research institutions (Popov E.V., Vlasov M.V., 2012).

Given the above-mentioned, we introduced the transaction rate of knowledge generation - a quantitative parameter, which describes the increase of knowledge under the increase of transaction costs (Popov E.V., Vlasov M.V., 2013)

The transaction rate of knowledge generation can be calculated with the following equation:

$v_{i j}=\frac{d k_{j}}{d T C_{i}}(1)$

$v_{i j} v_{i j}$-rate of increase in j-IR (results of intellectual activity) under the change in i-transaction cost; $d k_{j}$ - increase of $j$ - type of knowledge; $d T C_{i}$ - increase of i-transaction cost.

The parameter $v_{i j}$ allows one to estimate the degree of effect of a transaction cost on knowledge generation.

It should be noted at this step, that by knowledge we understand structured and systematized information meant to meet certain objectives and to support the lives of human beings. In additon, I. Nonaka and H. Tacheuchi [18], as well as B.Landwall and S. Borras [16] pointed out that the process of generation and application of knowledge requires dynamic transformation of both tangible and intangible knowledge (or explicit and implicit knowledge), as well as the codified and non-codified relations between actors. P. Nightingale [17] was certain that if tangible knowledge can inevitably be transferred with some friction along time and distance, intangible knowledge is integrated within a human being in order to understand and utilise information.

In the present research, the indicators of tangible knowledge will include: the number of papers published in research journals, the number of patents, as well as participation in exhibitions (the number of exhibitions attended and the number of exhibits). Intangible knowledge involves conference presentations. It is assumed that conference meetings discuss premature ideas not yet complete and verified, so they can only be referred to as intangible knowledge.

\section{Working Hypotheses}

Hence, the analysis of the above-mentioned bulk of research and authors' contributions has allowed us to set out a number of working hypotheses for further investigation.

Hypothesis 1: The performance of research work at a university subdivision, which can be described as knowledge generation in the form of papers published, patents obtained, participation in exhibitions and conferences, is determined to a large extent by transaction costs on research activity.

It should be mentioned here, that by transaction costs on research activity we understand the money allocated (and listed in accounting entries) to information search, travel expenses, representation, and other costs associated with research work. Salary and bonuses to the university's research and teaching staff are not included in transaction costs.

To provide comparability of the results, similar university subdivisions were chosen, i.e. a number of Institutes of the Ural Federal University named after the first Russian President B.N. Yeltsin. Since education institutes are known to 
be different considering the number of researchers, the second hypothesis is formulated as follows.

Hypothesis 2: The transaction rate of knowledge generation, which is expressed as the number those having a degree and PhD students.

To the opinion of the authors, the number of research developments, which are put on display at exhibitions, must correspond to the number of innovation enterprises established at the institutes involved. It brings about the third hypothesis.

Hypothesis 3: The transaction rate of knowledge generation, which is expressed as exhibition participation, is proportional to the number of economic units established at the university with a purpose of promoting the application of research achievements.

It seems evident that there is a connection between the patents obtained and the number of innovation enterprises.

Hypothesis 4: The transaction rate of knowledge generation, which is expressed in the form of patents obtained, is proportional to the number of economic units established at the university in order to utilise research achievements.

Assessment of intangible knowledge in terms of conference presentations deserves a particular attention. It is a belief of the authors of the present paper that the intensity of conference presentations must correspond to the number of contracts an educational institution signs, or, specifically, to the number of commercial contracts signed per an employee. Therefore, the fitth hypothesis may look as follows.

Hypothesis 5: The transaction rate of knowledge generation, which is expressed as the number of conference presentations, is proportional to the university contractual output per capita.

These working hypotheses have been verified by an extensive empirical study.

\section{Procedure of Empirical Study}

To provide the comparability of results, the representative sample included four large Institutes of the Ural Federal University named after B.N. Yeltsin specialized in sciences. For the sake of facilitation, the Institutes were assigned a serial number according to the number of faculty teaching staff: the first Institute - 297 persons, the second one - 254 persons, the third one -193 persons, and the forth one -126 persons, respectively.

When investigating the documentation of these Institutes, we filed the databases on the information effect and the output of research investigations in the years 2002 - 2011. It allowed us to obtain the empirical correlations of the tangible and intangible knowledge change under the change in transaction costs, as well as the transaction rate of knowledge generation.

Fig.1 demonstrates the correlation between an increase in the number of research papers published and an increase in spending on research in the $1^{\text {st }}$ Institution.

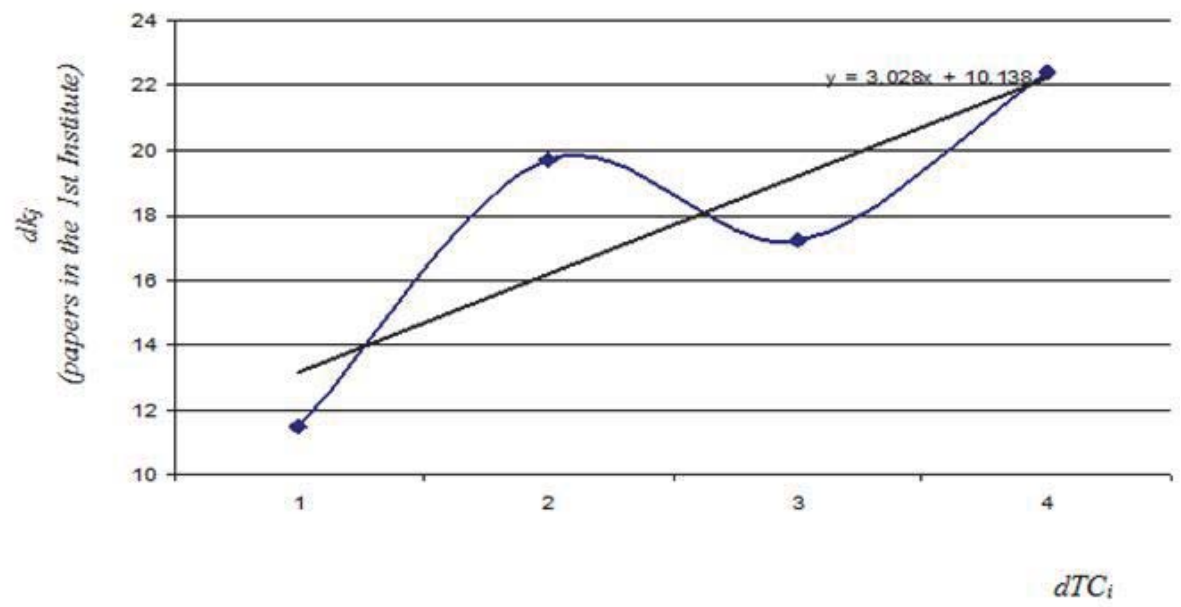

Fig 1. Dependence of an increase in the number of the papers published on an increase in the transaction costs on research

In the example given on Fig.1, $v_{11}$ is 3,03. The indicator $v_{i j}$ shows the share of the knowledge increase under $1 \%$ increase in the transaction costs. Similarly, the dependences of the transaction rates were drawn for all the knowledge types. 


\section{Data obtained and Verification of Hypotheses}

The research carried out has proved the first working hypothesis about strong correlation between transaction costs and research performance at universities (Tab.1).

Table 1. Coefficients of correlation between transaction costs and research output

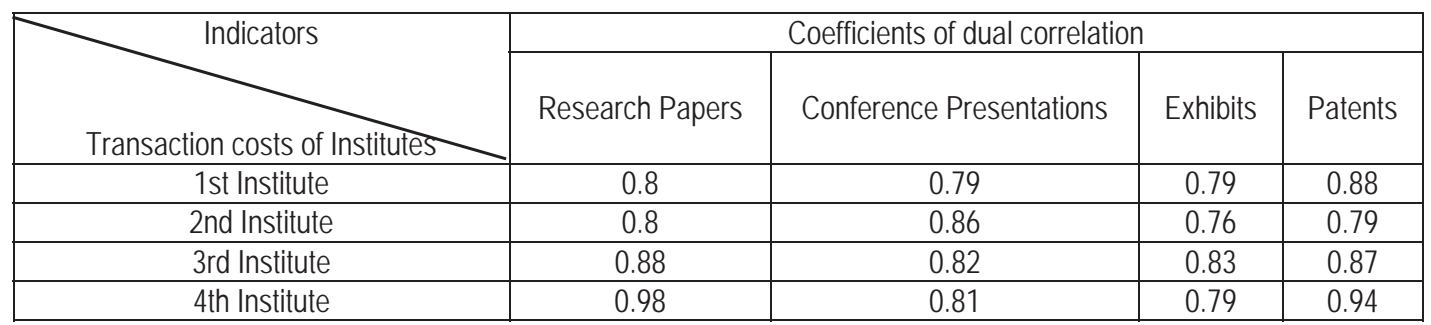

Hence, the empirical investigation proved the research performance in a university's subdivision, which is given as knowledge generation in the form of papers published, patents drawn, participation in exhibitions and conferences, to be determined by the transaction costs on research activity.

To verify Hypothesis 2, we compared the number of researchers, including those having a degree, as well as PhD students, with the transaction rates of knowledge generation in the form of published papers (Tab.2)

Table 2. Transaction rates of knowledge generation in terms of the number of papers and the number of researchers

\begin{tabular}{|c|c|c|}
\hline Institution & Rate of knowledge generation in the form of published papers & Number of researchers, persons \\
\hline 1st Institute & 3.09 & 344 \\
\hline 2nd Institute & 0.41 & 253 \\
\hline 3rd Institute & 1.49 & 165 \\
\hline 4th Institute & 0.21 & 173 \\
\hline
\end{tabular}

According to Table 2, Hypothesis 2 failed to be verified, because the transaction rate of knowledge generation tuned out to be disproportional to the number of researchers in an Institute. It seems likely that the transaction rate of knowledge generation in the form of papers published tends to be determined not by a total number of researchers but rather by their individual skills. This fact certainly requires further investigation.

Table 3 provides the results of empirical testing of Hypothesis 3 about the correlation between the knowledge generation rate in the form of participation in exhibitions and the number of economic units established at the university to utilise the research achievements, as well as the results of intellectual activity on the whole.

Table 3. Transaction rates of knowledge generation in terms of exhibit participation in exhibitions and the number of innovation economic units

\begin{tabular}{|c|c|c|}
\hline Institution & Rate of knowledge generation in the form of exhibits & Number of economic innovation units \\
\hline $1^{\text {st }}$ Institute & 3.09 & 10 \\
\hline Institute & 1.70 & 7 \\
\hline $3^{\text {rd }}$ Institute & 0.72 & 4 \\
\hline $4^{\text {th }}$ Institute & 0.04 & 2 \\
\hline
\end{tabular}

Table 3 undeniably proves the hypothesis that the transaction rate of knowledge generation in the form of exhibit participation in exhibitions is proportional to the number of economic units established at the university in order to utilise the research achievements.

It should be noted that the rate of a knowledge generation increase in the $1^{\text {st }}$ Institute is 0.04 . It seems likely that this type of knowledge has been created at the Institute, but the increase in the transaction costs in the given period has exceeded the knowledge increase. Supposedly, such minimal rate is the result of the minimal number of economic units established to promote the research achievement transfer.

The tangible knowledge in the second Institute generated via exhibition participation corresponds to the minimal 
correlation (0.76) and the maximal rate of intellectual results increase (3.09). Such significant rate is likely to be the result of the large number of economic units established with the Institute's participation to utilise the research developments and the results of intellectual activity of the given subdivision.

Table 4 depicts the empirical verification of Hypothesis 4 concerning the correlation between the knowledge generation in the form of patents and the number of innovation enterprises.

Table 4. Transaction rates of knowledge increase in terms of patents and the number of innovation economic units

\begin{tabular}{|c|c|c|}
\hline Institute & Knowledge generation rate in the form of patents & Number of innovation economic units \\
\hline $4^{\text {th }}$ Institution & 1.43 & 7 \\
\hline $3^{\text {rd }}$ Institution & 0.70 & 4 \\
\hline $1^{\text {st }}$ Institution & 0.30 & 2 \\
\hline $2^{\text {nd }}$ Institution & 0.29 & 10 \\
\hline
\end{tabular}

Table 4 shows that Hypothesis 4 has not been verified, because the transaction rate of knowledge generation expressed as the number of patents is not proportional to the number of economic units established at universities to apply the research developments. As well as with Hypothesis 2, application for patents seems mainly to be determined by the individual innovative characteristics of a particular researcher.

Table 5 gives the empirical data verifying Hypothesis 5 , which elucidates the correlation between the rate of knowledge generation during conference presentations and the total amount of contractual work done per one Institute's employee.

Table 5. Transaction rates of a knowledge increase in the form of conference presentations and the amount of contractual work per one employee a year

\begin{tabular}{|c|c|c|}
\hline Institution & $\begin{array}{c}\text { Knowledge generation rate in a form of conference } \\
\text { presentations }\end{array}$ & $\begin{array}{c}\text { Amount of contractual work per one employee a year, } \\
\text { thousands of rub. }\end{array}$ \\
\hline $1^{\text {st }}$ Institution & 2.59 & 259,1 \\
\hline $4^{\text {th }}$ Institution & 1.39 & 204,0 \\
\hline $2^{\text {nd }}$ Institution & 0.30 & 202,2 \\
\hline $3^{\text {rd }}$ Institution & 0.29 & 17,2 \\
\hline
\end{tabular}

The data given in Table 5 provides convincing evidence for the validity of Hypothesis 5 , which correlates the transaction rate of knowledge generation in the form of conference presentations and the amount of contractual work per one Institute's employee.

\section{Conclusion}

To summarize, the theoretical and empirical study undertaken to compare the dynamics of university research output, which is expressed quantitatively, with the dynamics of transaction funds spending has allowed us to reach the following conclusions.

First, the study has proved the hypothesis that transaction costs determine the university research performance in the form of papers published, patents obtained, and participation in exhibition and conferences.

Second, the study has empirically supported the hypothesis that the transaction rate of knowledge generation in the form of exhibit participation in exhibitions is proportional to the number of economic units established at Institutes to utilise the research developments.

Third, the empirically rejected hypotheses of correlation between the number of researchers and the transaction rate of research publication, as well as between the number of economic units and the transaction rate of patent registration, demonstrate the need to study these directions of intellectual activity in a greater detail.

Forth, it has been empirically proved that the transaction rate of knowledge generation in the form of conference presentations is proportional to the amount of contractual work per one institute's employee.

On the whole, the present study devoted to the transaction rates of knowledge generation in terms of various results of intellectual activity is of pilot character and might serve as a ground for researchers to draw attention to the potential of encouraging innovation by means of transaction costs. 
The research has produced the results of a world level. The practical relevance of this study is the possibility to use this data in planning, stimulation and increasing the efficiency of new knowledge generation at universities. The theoretical significance is the introduction of a new notion, i.e. the transaction rate of knowledge generation, in the arsenal of tools of knowledge economy.

\section{Acknowledgement}

The research is supported by the collaborative Program of the Ural Federal University named after the first President of Russia B.N.Yeltsin and Ural Branch of the Russian Academy of Sciences, Project No14-921-6-3 "Modeling of entrepreneurial strategies in the information-oriented society"

\section{References}

Arrow, K. J. Methodological Individualism and Social Knowledge, American Economic Review, 84(2), 1994, pp. 1-9

Bjørnåli E. S.and Gulbrandsen M. Exploring board formation and evolution of board composition in academic spin-offs // The Journal of Technology Transfer Volume 35, Number 1, 92-112

Clark B.R. The Higher Education System: Academic Organization in Cross-National Perspective. Berkeley: University of California Press, 1983. $315 \mathrm{p}$.

Nilsson A. S., Rikne A.and Bengtsson L. Transfer of academic research: uncovering the grey zone // The Journal of Technology Transfer Volume 35, Number 6, 617-636

North D. Strukture and Change in Economic History. - N.Y.: Norton, 1981.

Popov E.V., Vlasov M.V. Institutional Analysis for Economy of Knowledge //Economy \& Business. International Scientific Publication. 2008. Vol. 2. Part 1. pp 1116-1126.

Popov E.V., Vlasov M.V. Resource Differentiation of Knowledge //iBusiness. 2011. Vol.3. N 2, pp 211-217.

Popov E. V., Vlasov M.V., Veretennikova A.Y. Institutional Matrix of Knowledge Generation // Proceedings of the 12th European conference on knowledge management. 2011 vol 2 Pages: 780-788

Popov E. V., Vlasov M.V., Zubareva M.O. Developing Institutions of Knowledge Economy // Proceedings of the 12th European conference on knowledge management. 2011. vol 2 Pages: 789-800

Popov E.V., Vlasov M.V. Dependence of research productivity on transactional costs // Actual problems of Economics №5. 2012. pp.427-437

Popov E.V., Vlasov M.V. Knowledge generation within a firm as an object of institutional design Actual problems of Economics №1. 2013. pp.463-478.

Popov E.V., Vlasov M.V., Veretennikova A.Y. Institutional Planning of Knowledge Generation // Proceedings of the 14th European Conference on Knowledge Management. 2013. Vol 2.pp. 577-583.

Sorensen J. A. T., Chambers D.A. Evaluating academic technology transfer performance by how well access to knowledge is facilitated-defining an access metric // The Journal of Technology Transfer Volume 33, Number 5, 534-547

Visser Evert-Jan Logistic innovation in global supply chains: an empirical test of dynamic transaction-cost theory // GeoJournal. 2007. Volume: 70, Issue: 2-3, Pages: 213-226

Wallis J., North D. Measuring the Transactional Sector in American Economy, 1870-1970 // Long-term factors in American Economic Growth. Chicago: University of Chicago Press, 1986. P. $95-162$

Williamson O. E. Transaction-Cost Economics: the Governance of Contractual Relations //Journal of Low and economics. 1979. Vol. 22. No. 2.

Williamson O.E. Strategizing, Economizing and Economic Organization //Strategic Management Journal. 1991. Vol. 12. P. 75-94

Zinkhan G. M. Accessing Academic Research Through an E-Database:Issues of Journal Quality and Knowledge Use // Journal of the Academy of Marketing Science.Volume 32, No. 4, pages 369-370. 